\title{
Association of Hyperuricaemia with Perinatal Outcome in Pregnancy Induced Hypertension
}

\author{
S AKTER ${ }^{\mathrm{a}}$, S SULTANA ${ }^{\mathrm{b}}$, SR DABEE ${ }^{\mathrm{c}}$
}

\begin{abstract}
Summary:
The high serum uric acid concentration correlates with the degree of severity of the pregnancy induced hypertension (PIH) and perinatal outcome. In this context, maternal serum uric acid level is reported to be one of the prognostic factor for determination of perinatal outcome. Based on the existing data, the present prospective study was undertaken in the Department of Obstetrics and Gynaecology, BIRDEM Academy, from January to December, 2010. Out of 120 women, 60 suffering from PIH (severe preeclampsia and eclampsia) served as group $I$ and 60 normotensive women at third trimester of pregnancy served as group II.
\end{abstract}

This study showed that mean $( \pm S D)$ serum uric acid was significantly elevated in group I PIH patients (7.21 \pm 1.81

Introduction:

Many clinical and biochemical parameters have been used to detect pregnancy induced hypertension (PIH) and to assess its severity. Unfortunately most of the available parameters till date are neither specific nor always sensitive. In preeclamptic patients with mild pathologic lesions documented by renal biopsy, serum uric acid (SUA) was elevated ${ }^{1}$. In more severe cases with azotemia, SUA was higher ${ }^{2}$. The pathogenesis of hyperuricaemia in PIH has not yet been determined. Chesely and Williams stated that in PIH there was impaired glomerular filtrate rate (GFR) and an increased tubular reabsorption of uric acid, leading to impaired uric acid clearance ${ }^{3}$. But Pollak and Nettles reported that decreased uric acid clearance was the result of

a. Dr. Saida Akter, Private Practice, 52/7 East Raja Bazar (2nd floor), Dhaka.

b. Dr. Sharmin Sultana, Medical Officer, 200 Bedded Hospital, Narayanganj.

c. Dr. Seema Rani Dabee, Junior Consultant, 20 Bedded Hospital, Amin Bazar, Savar.

Address of Correspondence: Dr. Saida Akter, 52/7 East Raja Bazar (2nd floor), Dhaka 1215, Phone: 01711824262.

Received: 20 April, 2013

Accepted: 30 March, 2014 mg/dl) compared to group II normotensive pregnancy $(4.40 \pm 0.84 \mathrm{mg} / \mathrm{dl})$.

In group I PIH patients, 39 (86\%) had adverse perinatal outcome (preterm, IUGR, stillbirth), and 6 (13.3\%) term and healthy deliveries when serum uric acid level was $>6 \mathrm{mg} / \mathrm{dl}$. Current study showed that there was positive and statistically significant relationship between diastolic blood pressure and hyperuricaemia in group I PIH patients $(r=+0.359, P<0.01)$.

This study also showed that in group I PIH patients, when serum uric acid increased, birth weight significantly decreased ( $r=0.279, P<0.05)$.

Key words: Fetal outcome, Hyperuricaemia, PIH.

(J Banagladesh Coll Phys Surg 2014; 32: 124-129)

enhanced tubular reabsorption or inhibited tubular secretion or both ${ }^{1}$.

Hypertensive disorders during pregnancy increases the maternal and infant risk. The greatest impact is associated with pregnancy specific syndrome ${ }^{4}$. Preeclampsia, conventionally diagnosed by gestational onset of hypertension and proteinuria, has increased perinatal mortality by five fold and kills 50,000 women yearly worldwide ${ }^{4,5}$. Gestational hypertension without proteinuria has much less of an adverse effect on maternal or fetal outcome, whereas the major risk from hypertension that antedates pregnancy is the superimposition of preeclampsia ${ }^{6}$.

Elevated uric acid is another component of the preeclampsia syndrome that was recognized many years ago $^{7}$. It is one of the most consistent and earliest detectable changes in preeclampsia and has been cited as a better predictor of fetal risk than blood pressure ${ }^{8,9}$. Despite these findings, uric acid assessment in the evaluation of PIH has fallen into disfavour. A recent publication reported that the utility of measuring serum uric acid levels in PIH is limited ${ }^{10}$. 
Association of elevated serum uric acid with development of hypertension is established outside of pregnancy, less is known about whether women who begin pregnancy with elevated serum uric acid have an increased risk of developing hypertensive disease during pregnancy or vice versa. In healthy pregnancies, uric acid decreases from an average of $4.2 \mathrm{mg} / \mathrm{dl}$ pregnancy to $3.1 \pm 1.1 \mathrm{mg} / \mathrm{dl}$ in the first trimester, and slowly increases during gestation to an average of $5.1 \pm 1.2 \mathrm{mg} /$ $\mathrm{dl}$ from 35 weeks of gestation to term ${ }^{11,12}$. It has been reported that gestational hypertension with hyperuricaemia or preeclampsia with hyperuricaemia defines a more severe form of hypertensive disease, with increased risk of adverse fetal outcome including preterm birth and small for gestational age (SGA) compared to women with gestational hypertension or preeclampsia without hyperuricaemia ${ }^{13}$.

Hyperuricaemia has received much attention and debate recently with regard to its utility as a marker for preeclampsia and as a predictor of adverse maternal and fetal outcome ${ }^{14}$. Stander and Cadden in 1945 were the first to demonstrate a high correlation between the severity of PIH and concentration of serum uric acid level. Serum uric acid level is one of the parameter used in early diagnosis of PIH. Hyperuricemia in PIH is a result of primarily of decreased renal clearance of uric acid, a decrease that exceeds the reduction in glomerular filtration rate and creatinine clearance ${ }^{3}$.

In women with PIH, hyperuricemia was associated with shorter gestations and smaller birth weight centiles and increased risk of preterm birth and small for gestational age (SGA) infants. Hyperuricemia increased the risk of these outcomes in the presence and absence of proteinuria. Risk was also increased in a small group of women with hyperuricemia and proteinuria without hypertension. Women with only hypertension and hyperuricemia have similar or greater risk as women with only hypertension and proteinuria. Those with hypertension, proteinuria and hyperuricemia have greater risk than those with hypertension and proteinuria alone. The risk of these outcomes increased with increasing uric acid ${ }^{13}$.

In the light of evidences from different studies, in the present study we tried to find out whether raised serum uric acid has an adverse effect on perinatal outcome in severe preeclampsia and eclampsia. We also tried to find out if serum uric acid concentration can be used as a screening test for the prediction of perinatal prognosis.

\section{Materials and Methods:}

This prospective study was carried out in the Department of Obstetrics and Gynaecology, Bangladesh Institute of Research and Rehabilitation, Endocrine and Metabolic Disorders Hospital (BIRDEM), and Dhaka Medical College Hospital (DMCH), Dhaka, during January and December, 2010.

The study population consisted of 60 women suffering from PIH (severe preeclampsia, eclampsia) (Group I) and 60 normotensive women (Group II) attending Department of Obstetrics and Gynaecology, BIRDEM and Dhaka Medical College Hospital (DMCH).

Inclusion Criteria: Third trimester pregnant women suffering from PIH (preeclampsia and eclampsia) (Group I) and normotensive (Group II). Exclusion criteria: Patients with known chronic renal disease, patients suffering from diabetes mellitus, diagnosed patients of hepatic dysfunction, and patients suffering from gout.

Ethical consideration: Permission was obtained from Ethical Review Committee of BIRDEM. Before inclusion in the study, informed written consents was obtained from each patient.

Data processing: Data of each individual participants was recorded on a predesigned data collection sheet, and appropriate statistical analyses were done using computerbased software (SPSS).

Collection of blood sample: Two milliliter of random venous blood was collected from antecubital vein of the pregnancy induced hypertension and normotensive subjects taking all aseptic precautions. Blood was drawn single time from each subject and submitted within half an hour to the laboratory for analysis.

Laboratory method: Estimation of serum uric acid concentration was done by enzymatic colorimetric method.

Dependent or outcome variables: Preterm, stillbirth, IUGR, and term and healthy babies. Independent variables: Hypertension and serum uric acid.

\section{Results:}

Table I shows characteristics of the study population. Both mean $( \pm \mathrm{SD})$ systolic and diastolic blood pressure 
was significantly high $(\mathrm{P}<0.001)$ in group I (159.17 \pm 12.53 and $107.73 \pm 8.80 \mathrm{mmHg}$ ) compared to group II (107.00 \pm 9.26 and $68.67 \pm 7.69 \mathrm{mmHg})$. Mean $( \pm$ SD) serum uric acid was also significantly high in group I $(7.21 \pm 1.81 \mathrm{mg} / \mathrm{dl})$ compared to group II $(4.40 \pm 0.84 \mathrm{mg} / \mathrm{dl})$. Serum uric acid was normal ( $£ 6$ $\mathrm{mg} / \mathrm{dl}$ ) in 15 (25\%) and 54 (90\%), and raised (>6 mg/ $\mathrm{dl})$ in 45 (75\%) and 6 (10\%) women in group I and group II, respectively.

Table II shows pregnancy outcome. There were 13 (21.7\%) and 53 (88.3\%) term and vaginal deliveries, $24(40 \%)$ and 3 (5\%) preterm deliveries, 9 (15\%) and 2 (3.3\%) IUGRs, and 14 (23.3\%) and 2 (3.3\%) stillbirth in group I and group II, respectively. In group II significantly high $(\mathrm{P}<0.001)$ number of deliveries were term and vaginal. Mean $( \pm$ SD) birth weight was significantly low $(\mathrm{P}<0.001)$ in group II $(2.28 \pm 0.19 \mathrm{~kg})$ compared to group II $(2.75 \pm 0.26 \mathrm{~kg})$. Birth weight was significantly $(\mathrm{P}<0.001)$ low $(<2.5 \mathrm{~kg})$ in $50(83.3 \%)$ babies of group I compared to 7 (11.7\%) babies of group II, and vaginal $<32.5 \mathrm{~kg}$ ) in 10 (16.7\%) and 53 (88.3\%), in group I and group II, respectively

Table III shows association between hyperuricaemia (serum uric acid $>6 \mathrm{mg} / \mathrm{dl}$ ) and fetal outcome in group I women. Serum uric acid level was $£ 6 \mathrm{mg} / \mathrm{dl}$ in 15 (25\%) and $>6 \mathrm{mg} / \mathrm{dl}$ in 45 (75\%) group I women. Fetal outcome was term and healthy in 7 (46.7\%) and 6 (13.3\%), preterm in 4 (26.7\%) and 20 (44.4\%), IUGR

Table-I

\begin{tabular}{|c|c|c|c|}
\hline \multicolumn{4}{|c|}{ Characteristics of the study subjects } \\
\hline Variables & $\begin{array}{c}\text { Group I } \\
(\mathrm{n}=60)\end{array}$ & $\begin{array}{c}\text { Group II } \\
(\mathrm{n}=60)\end{array}$ & P value \\
\hline \multicolumn{4}{|c|}{ Systolic blood pressure (mmHg) } \\
\hline Mean \pm SD & $159.17 \pm 12.53$ & $107.00 \pm 9.26$ & $0.0001^{* * *}$ \\
\hline \multicolumn{4}{|c|}{ Diastolic blood pressure (mmHg) } \\
\hline \multicolumn{4}{|c|}{ Serum uric acid (mg/dl) } \\
\hline \multirow[t]{2}{*}{ Mean \pm SD } & $7.21 \pm 1.81$ & $4.40 \pm 0.84$ & $0.0001^{* * *}$ \\
\hline & No. & (\%) & \\
\hline$\leq 6$ & $(25.0)$ & $(90.0)$ & $0.0001^{* * *}$ \\
\hline$>6$ & (75.0) & (10.0) & \\
\hline
\end{tabular}

Unpaired Student's 't' test/Chi square test, $* * *=$ significant $(\mathrm{P}<0.001)$

\section{Table-II}

\begin{tabular}{|c|c|c|c|c|c|}
\hline \multicolumn{6}{|c|}{ Fetal outcome } \\
\hline \multirow[t]{2}{*}{ Variables } & \multicolumn{2}{|c|}{$\begin{array}{l}\text { Group I } \\
(\mathrm{n}=60)\end{array}$} & \multicolumn{2}{|c|}{$\begin{array}{c}\text { Group II } \\
(\mathrm{n}=60)\end{array}$} & \multirow[t]{2}{*}{ P value } \\
\hline & No. & $(\%)$ & No. & $(\%)$ & \\
\hline Fetal outcome & & & & & $0.0001^{* * *}$ \\
\hline Term and healthy & 13 & (21.7) & 53 & $(88.3)$ & \\
\hline Preterm & 24 & $(40.0)$ & 3 & $(5.0)$ & \\
\hline IUGR & 9 & $(15.0)$ & 2 & (3.3) & \\
\hline Stillborn & 14 & (23.3) & 2 & (3.3) & \\
\hline Birth weight (kg) & & & & & $0.0001^{* * *}$ \\
\hline$<2.5$ & 50 & (83.3) & 7 & (11.7) & \\
\hline$\geq 2.5$ & 10 & (16.7) & 53 & (88.3) & \\
\hline Mean \pm SD & $2.28 \pm 0.19$ & $2.75 \pm 0.26$ & $0.0001^{* * *}$ & & \\
\hline
\end{tabular}

Chi square test/Unpaired Student's 't' test, *** = significant $(\mathrm{P}<0.001)$ 


\section{Table-III}

Association between serum uric acid level and fetal outcome in group I subjects

\begin{tabular}{|c|c|c|c|c|c|}
\hline \multirow{3}{*}{ Variables } & \multicolumn{4}{|c|}{ Serum uric acid level (mg/dl) } & \multirow{3}{*}{$P$ value } \\
\hline & \multicolumn{2}{|c|}{$\leq 6(n=15)$} & \multicolumn{2}{|c|}{$>6(n=45)$} & \\
\hline & No. & $(\%)$ & No. & $(\%)$ & \\
\hline Fetal outcome & & & & & $0.056^{\mathrm{ns}}$ \\
\hline Term and healthy & 7 & $(46.7)$ & 6 & $(13.3)$ & \\
\hline Preterm & 4 & $(26.7)$ & 20 & $(44.4)$ & \\
\hline IUGR & 2 & (13.3) & 7 & $(15.6)$ & \\
\hline Stillborn & 2 & (13.3) & 12 & $(26.7)$ & \\
\hline Normal/adverse outcome & & & & & $0.007^{* *}$ \\
\hline Term and normal & 7 & $(46.7)$ & 6 & (13.3) & \\
\hline $\begin{array}{l}\text { Adverse (preterm, } \\
\text { IUGR, stillborn) }\end{array}$ & 8 & (53.3) & 39 & $(86.7)$ & \\
\hline
\end{tabular}

Chi square test, $\mathrm{ns}=$ not significant $* *=$ significant $(\mathrm{P}<0.01)$

in 2 (13.3\%) and 7 (15.6\%), and stillborn in 2 (13.3\%) and $12(26.7 \%)$ in women with serum uric acid level $£ 6$ $\mathrm{mg} / \mathrm{dl}$ and $>6 \mathrm{mg} / \mathrm{dl}$, respectively. When fetal outcome was grouped into term and healthy, and adverse (preterm, IUGR, stillborn), hyperuricaemia showed significant $(\mathrm{P}<0.01)$ association. Term and vaginal deliveries were achieved in 7 (46.7\%) and 6 (13.3\%), and adverse (preterm, IUGR, stillbirth) in 8 (53.3\%) and 39 (86.7\%) when serum uric acid level was $£ 6$ mg/ dl and $>6 \mathrm{mg} / \mathrm{dl}$, respectively.

Fig. 1 shows negative and statistically significant relation $(r=0.0279, \mathrm{P}<0.05)$ between serum uric acid

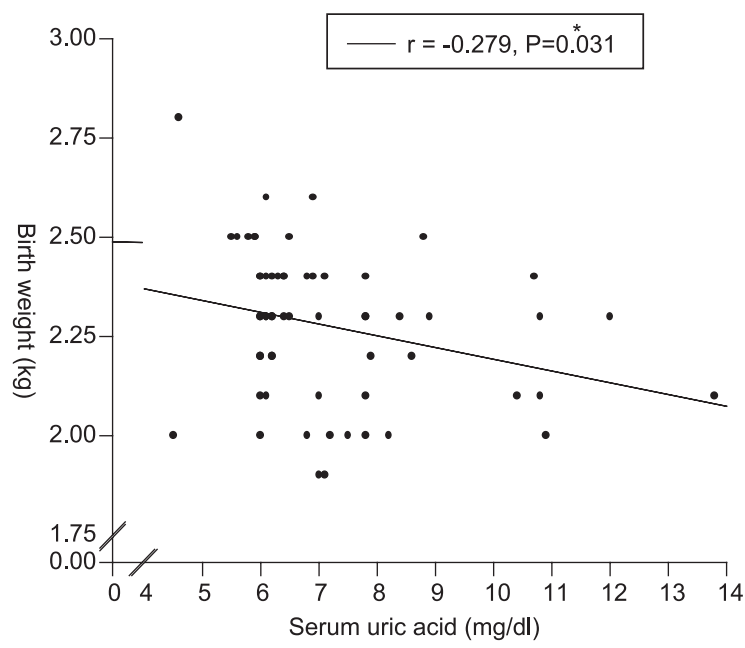

Fig.-1: Relationship between serum uric acid and birth weight of group-I babies level and birth weight of group I babies. Fig. 2 shows positive and statistically significant relationship between serum uric acid and diastolic blood pressure $(r=+0.359$, $\mathrm{P}<0.01$ ) in group I women.

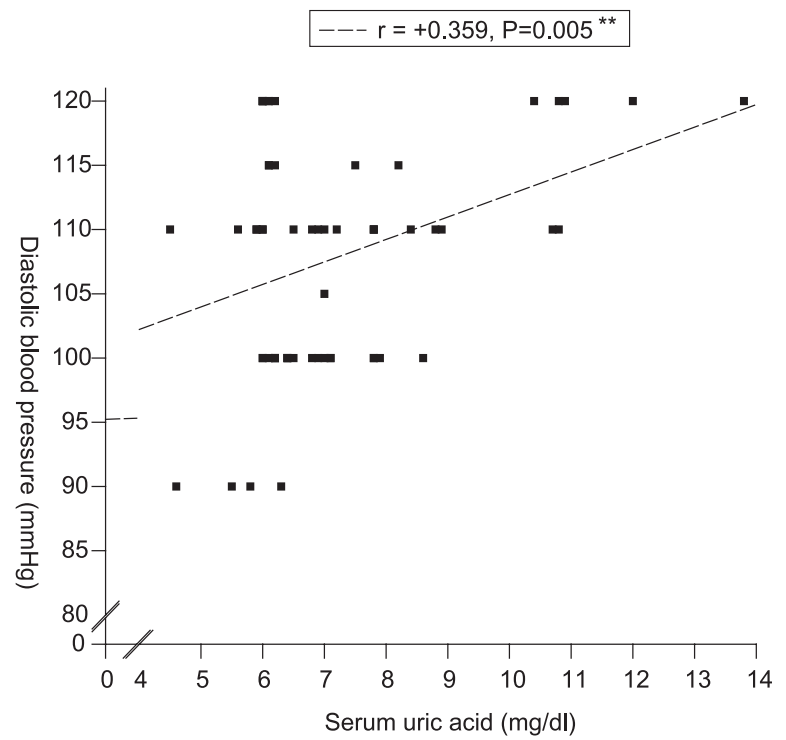

Fig.-2: Relationship between serum uric acid and diastolic blood pressure in group-I subjects

\section{Discussion:}

Perinatal complications are correlated with hypertensive disorders of pregnancy. In this context, the maternal serum uric acid level is found to be one of the prognostic 
factor in determining perinatal outcome. This study showed that serum uric acid was significantly elevated $(\mathrm{P}<0.001)$ in group I PIH patients compared to group II normotensive pregnant women. Mean $( \pm S D)$ and median serum uric acid level of group I (severe preeclampsia, eclampsia) was $7.21 \pm 1.81$ and $6.50 \mathrm{mg} /$ $\mathrm{dl}$, and in group II (normotensive pregnant women) was $4.40 \pm 0.84$ and $4.10 \mathrm{mg} / \mathrm{dl}$, respectively.

Status of serum uric acid of the study subjects showed that serum uric acid was $£ 6 \mathrm{mg} / \mathrm{dl}$ in 15 (25\%) of group I and 54 (90\%) of group II subjects, and was $>6 \mathrm{mg} / \mathrm{dl}$ in 45 (75\%) of group I and 6 (10\%) of group II subjects $(\mathrm{P}<0.001)$.

Association of serum uric acid level with fetal outcome in group I showed that, out of 15 babies whose mothers had serum uric acid level £6 mg/dl, 7 (46.7\%) babies achieved term and vaginal delivery, and 8 (53.3\%) had adverse outcome (preterm, IUGR, stillborn), and out of 45 babies whose mothers had serum uric acid level $>6$ $\mathrm{mg} / \mathrm{dl}, 6$ (13.3\%) babies achieved term and vaginal delivery while 39 (86.7\%) had adverse outcome. Serum uric acid level of mothers showed significant association with fetal outcome $(\mathrm{P}<0.01)$. Maximum number of adverse outcomes belonged to serum uric acid level $>6$ $\mathrm{mg} / \mathrm{dl}$ compared to $£ 6 \mathrm{mg} / \mathrm{dl}$. Similar observation was made by Yassaee ${ }^{15}$.

Current study showed that both systolic (159.17 \pm 12.53 vs $107.00 \pm 9.26 \mathrm{mmHg}$ ) and diastolic $(107.83 \pm 8.80$ vs $68.67 \pm 7.69 \mathrm{mmHg}$ ) blood pressure were significantly high in group I than group II. Positive and statistically significant relationship between serum uric acid and diastolic blood pressure in group I was also observed. Redman et al., Varma and Mustaphi et al. also reported similar findings ${ }^{16} 18$.

The present study showed that mean birth weight of babies was significantly lower $(\mathrm{P}<0.001)$ in group I (mean \pm SD $2.28 \pm 0.19$, median $2.30 \mathrm{~kg}$ ) compared to group II (mean \pm SD $2.75 \pm 0.26$, median $2.70 \mathrm{~kg}$ ). Relationship between serum uric acid level of mothers and fetal birth weight in group I showed that when serum uric acid level increased, birth weight significantly decreased $(r=0.279, P<0.05)$. This was supported by the findings of Roberts et al. ${ }^{13}$ They examined fetal growth adjusted for gestational age, hyperuricemia with pregnancies who had neither PIH nor high serum uric acid, the risk of an infant having birth weight $£ 10$ th or £5th centile was significantly higher in the hyperuricemic group. This finding apparently and weakly supported the current correlation between birth weight and hyperuricemia.

Although this study showed adverse perinatal outcomes were more in hyperuricemia, supported by many previous studies, another study carried out by Lim et al. showed as a diagnostic test, serum uric acid was neither sensitive nor specific when used to diagnose preeclampsia in the setting of new hypertension ${ }^{10}$. There was one obvious limitation to this study, the women were socioeconomically diverse, data came from tertiary center, which may have limited generalizability.

Despite the fact that hyperuricemia is not a conventionally used diagnostic criteria for PIH and nor typically considered as useful aid to management, several observations have suggested that the presence of hyperuricemia may identify a form of PIH with increased risk ${ }^{13}$.

Meanwhile, this study showed that hyperuricemia with maternal hypertension was associated with perinatal morbidity and mortality, and premature intervention of pregnancy. Therefore, estimation of serum uric acid does help to identify fetus at risk of developing adverse perinatal consequences and to assess severity of the disease. Laboratory investigations of serum uric acid is simple and can be easily performed in any laboratory.

In this study, the relationships we observed were examined prospectively and tests performed to determine whether the information positively and effectively affected perinatal outcome. It is quite likely based on prior studies that uric acid may be used in the complex decision making for delivery, the cornerstone of management of women with PIH. This has been supported by Odendaal and Pienaar. ${ }^{19}$ An important question to be resolved is whether, as suggested by our data in this study, the adverse perinatal outcomes were associated with likely presence of concomitantly increased uric acid. Finally, this finding encourages a reevaluation of the current classification of PIH in relation to pregnancy outcome using serum uric acid and other markers of pathophysiology.

\section{Conclusion:}

There have been some conflicting and significant reports in the literature regarding usefulness of serum uric acid estimation in women with PIH. The present study was 
carried out as an attempt to critically reappraise the association of hyperuricemia with adverse perinatal consequences by this simple biochemical test. From this study, it appears that there was significant and positive relationship between hyperuricemia and adverse perinatal outcome. In normal pregnancy, serum uric acid usually reduces in early and mid pregnancy and rises to normal level in late pregnancy. It is appropriate and useful to estimate the serum uric acid level in women at increased risk to obtain satisfactory pregnancy outcome and ensure appropriate management of pregnancy complicated by pregnancy induced hypertension.

\section{References:}

1. Pollak VE, Nettles JB. The kidney in toxoemia of pregnancy: a clinical and pathological study based in renal biopsies. Medicine 1960; 39:469.

2. Fedel HE, Sabour MS, Mahravi M, et al. Serum uric acid in preeclampsia and eclampsia. J Egypt Med Assoc 1969; 52:12.

3. Chesley LC, Williams LO. Renal glomerular and tubular function in relation to hyperuricemia of preeclampsia and eclampsia. Am J Obstet Gynecol 1945; 50:367.

4. Roberts JM. Pregnancy related hypertension. In: Creasy RK, Resnik R, editors. Maternal fetal medicine. 4th ed. Philadelphia: WB Saunders, 1998: 83372.

5. Duley L. Maternal mortality associated with hypertensive disorders of pregnancy in Africa, Asia, Latin America and the Caribbean. Br J Obstet Gynaecol 1992; 99:547 53.

6. Group NHBPEPW. Report of the National High Blood Pressure Education Program Working Group on High Blood Pressure in Pregnancy. Am J Obstet Gynecol 2000; 183:S1 22.

7. Chesley LC. Hypertensive disorders of pregnancy. New York: Appleton Century Crofts; 1978.
8. Redman CW, Beilin LJ, Bonnar J, Wilkinson RH. Plasma urate measurements in predicting fetal death in hypertensive pregnancy. Lancet 1976; 1:1370 3.

9. Chesley LC. Diagnosis of preeclampsia. Obstet Gynecol 1985; 65:423 5 .

10. Lim KH, Friedman SA, Ecker JL, Kao L, Kilpatrick SJ. The clinical utility of serum uric acid measurements in hypertensive diseases of pregnancy. Am J Obstet Gynecol 1998; 178:1067 71.

11. Powers RW, Bodnar LM, Ness RB, et al. Uric acid concentrations in early pregnancy among preeclamptic women with gestational hypertension hyperuricemia at delivery. Am J Obstet Gynecol 2006; 194:160.

12. Lind T, Godfrey KA, Otun H, Philips PR. Changes in serum uric acid concentrations during normal pregnancy. Br J Obstet Gynaecol 1984; 91:128 32.

13. Roberts JM, Bodnar LM, Lain KY, et al. Uric acid is an important as proteinuria in identifying fetal risk in women with gestational hypertension. Hypertension 2005; 46: 12639.

14. Parrish M, Griffin M, Morris R, et al. Hyperuricemia facilitates the prediction of maternal and perinatal adverse outcome in patients with severe/superimposed preeclampsia. J Matern Fetal Neonatal Med 2010; 23:1451 5.

15. Yassaee F. Hyperuricemia and perinatal outcomes in patients with severe preeclampsia. Int J Med Sci 2003; 28.

16. Redman C, Beilin L, Bonnar J, Wilkinson R. Plasma urate measurements in predicting fetal death in hypertensive pregnancy. Lancet 1976; 1:1370 3.

17. Varma TR. Serum uric acid levels as an index of foetal prognosis in pregnancies complicated by pre existing hypertension and preeclampsia of pregnancy. Int J Gynaecol Obstet 1982; 20:401 8.

18. Mustaphi R, Gopalan S, Dhaliwal L, Sarkar AK. Hyperuricemia and pregnancy induced hypertension: Reappraisal. Indian J Med Sci 1996; 50:68 71.

19. Odendaal HJ, Pienaar ME. Are high uric acid levels in patients with early preeclampsia an indication for delivery? S Afr Med J 1997; 87(2 Suppl):213 8. 